\title{
Biologics did not reduce surgery rate but prolonged remission duration in patients with ulcerative colitis: analysis of a large retrospective Japanese cohort
}

\section{Yuya Yokoyama}

Chiba University Hospital

\section{Yuki Ohta}

Chiba University Hospital

\section{Sadahisa Ogasawara}

Chiba University Hospital

Jun Kato ( $\square$ kato.jun@chiba-u.jp )

Chiba University

\section{Ryoko Arai}

Chiba University

Hirotaka Koseki

Chiba Aoba Municipal Hospital

\section{Masaya Saito}

Seikeikai Chiba medical center

\section{Tatsuya Kaneko}

Chiba University

Mamoru Tokunaga

Chiba University

Hirotaka Oura

Chiba University

\section{Tsubasa Oike}

Chiba University

\section{Yushi Imai}

Chiba University

Kengo Kanayama Chiba University

\section{Naoki Akizue}

Chiba University

Junichiro Kumagai

Chiba University

Takashi Taida 
Chiba University

\section{Kenichiro Okimoto}

Chiba University

\section{Keiko Saito}

Chiba University

\section{Yoshihiko Ooka}

Chiba University

\section{Tomoaki Matsumura}

Chiba University

\section{Tomoo Nakagawa}

Chiba University

\section{Makoto Arai}

Chiba University

\section{Tatsuro Katsuno}

Chiba University

\section{Yoshihiro Fukuda}

Seikeikai Chiba medical center

\section{Yoshio Kitsukawa}

Chiba Aoba Municipal Hospital

\section{Naoya Kato}

Chiba University

\section{Research Article}

Keywords: ulcerative colitis, inflammatory bowel disease, biologics, antitumor necrosis factor therapy.

Posted Date: February 18th, 2022

DOI: https://doi.org/10.21203/rs.3.rs-1265976/v1

License: (c) (i) This work is licensed under a Creative Commons Attribution 4.0 International License. Read Full License 


\section{Abstract}

Objective: To gain better understanding of the effects of biologics, we evaluated clinical outcomes in patients with moderate to severe exacerbations of ulcerative colitis (UC).

Methods: This retrospective, multicenter study retrieved the entire clinical courses of UC patients who began treatments between 2004 and 2018. All exacerbations and clinical parameters, including treatment details for exacerbations and both remission and re-exacerbation dates, were identified during the observation period. Two different endpoints, the cumulative incidence rates of surgical resection and reexacerbation, were evaluated separately in moderate to severe exacerbation events.

Results: Among 1401 patients, 1626 exacerbation events were determined according to a partial Mayo score (remission: <2, mild: 2-4, moderate: $5-7$, and severe: $>7$ ). During the observation period, as administration rates of biologics increased, both surgical resection and hospitalization rates decreased, for 959 moderate to severe exacerbation events. We confirmed that biologics significantly reduced the cumulative re-exacerbation rate in moderate to severe exacerbation events during the study period compared with suboptimal therapies (a 0.507 -fold decrease risk according to COX regression analysis, $P$ $<0.001)$. However, they had not enough impact in reducing the cumulative incidence rate of surgical resection in moderate to severe exacerbation events that were corticosteroid-refractory or dependent (a 0.878 -fold decrease risk according to COX regression analysis, $P=0.606$ ).

Conclusions: Biologics may improve remission duration, but these agents had no significant impact in reducing the risk of surgical resection in moderate to severe active UC.

\section{Introduction}

Ulcerative colitis (UC), a subtype of inflammatory bowel disease (IBD), is a chronic inflammatory disease of the colon, representing the most common distressing period of productive age and resulting in disability [1]. Although UC is associated with the Caucasian population in the United States and Europe, its incidence in newly developed countries, primarily in Asia, has been increasing rapidly over the past few decades [2-5]. Japan ranks second in the world in terms of the number of UC patients after the United States [3-6]. The sharp increase of UC cases in Japan appears to be associated with Westernized diets and environments, which affect the intestinal microbiome and increase the risk for UC in genetically susceptible individuals $[7,8]$.

The primary treatment goals for UC patients are to induce and maintain remission. Specifically, a surgical resection of the total colon due to an induction failure and an early re-exacerbation after remission are the two worst clinical outcomes in patients with UC [1]. 5-aminosalicylates (5-ASA), which are antiinflammatory agents, are the major choice of treatment to induce and maintain remission in patients with mild to moderate active UC $[9,10]$. Corticosteroids are a classical and most widely used treatment for inducing remission based on their confirmed high rates of immediate effectiveness [11-13]. Over half a century since the first report, corticosteroids remain the first-line treatment for moderate to severe 
exacerbations or when 5-ASA proves ineffective, as recommended by global guidelines [14-17]. However, roughly one-third of patients have not achieved clinical response or remission, while almost two-thirds of patients had required reintroduction of corticosteroids within two years and even they had achieved remission $[18,19]$.

During the past two decades, there has been a dramatic paradigm shift in UC treatment with the introduction of biologics, primarily antitumor necrosis factor (anti-TNF) therapy, for both inducing and maintaining remission $[9,14,15,17]$. Well-designed randomized controlled trials have confirmed that biologics, including infliximab, adalimumab, golimumab, and vedolizumab, both improved induction and sustained remission rates compared with placebo in patients with moderate to severe active UC who had failed corticosteroid therapy or who had a history of corticosteroid refractory or dependent [20-24]. The rates of surgical resection and hospitalization in UC patients have decreased in both Eastern and Western populations $[25,26]$. However, the effects of biologics for patients with active UC, particularly focusing on overall long-term effectiveness of these new agents for maintaining remission, remain controversial and have not yet been clarified sufficiently. Therefore, this study was conducted to evaluate the clinical outcomes of biologics in UC patients with moderate to severe exacerbations using a large retrospective Japanese cohort over a long observation period.

\section{Methods}

\section{Study population and study design}

Chiba City is inhabited by approximately 1 million people (the 12th largest population in Japan) with less migration compared with the central metropolitan area of Japan. Chiba University Hospital, Chiba Aoba Municipal Hospital, and Chiba Medical Center are the only three institutions to which well-trained specialists in IBD belong.

We retrospectively investigated the entire clinical courses of UC patients by reviewing the electronic medical records (EMR) in three institutions and identified all exacerbations according to the partial Mayo score [27]. We identified all exacerbation events during the entire observation period and acquired the following data: the date of exacerbation diagnosis, laboratory data and disease extent at the time of exacerbation, requirement of hospitalization, and medical treatments for exacerbation.

All participating hospitals received approval from IRB. The Institutional Review Board of Chiba University Hospital approved this study (approval number: 3399).

\section{Informed consent}

was waived because this was a survey study using medical records and no written or verbal consent could be obtained from the research subjects. However, materials regarding opting out were posted to give patients the opportunity to refuse to participate in the study. We conduct our research in accordance with the "Ethical Guidelines for Medical Research Involving Human Subjects" established by the Ministry 
of Education, Culture, Sports, Science and Technology and the Ministry of Health, Labour and Welfare of Japan.

\section{Treatment strategies for UC}

UC diagnosis was based on the combination of conventional clinical, endoscopic, radiological, and pathological criteria [28]. 5-ASA is the first choice for inducing and maintaining remission in patients with mild to moderate active UC. Corticosteroids are introduced for patients with moderate to severe active UC, and/or in those unresponsive to 5-ASA, and are tapered off over 8-12 weeks. Biologics (infliximab, adalimumab, golimumab and vedolizumab), and immunomodulators (i.e., thiopurines; azathioprine/6mercaptopurine), were considered in case of corticosteroid failure. Calcineurin inhibitors, apheresis, and surgical resection were considered rescue medical treatments in patients who were unresponsive to corticosteroids. Since tofacitinib was approved in Japan in May 2018 and had been use only a few patients, we excluded these patients form this study.

\section{Definition of exacerbations according to partial Mayo score}

The degree of exacerbations during the observation period was assessed according to the partial Mayo score using three noninvasive parameters (stool frequency, rectum bleeding, and physician's global assessment) [26]. Each of the three categories were rated from 0 to 3 that was summed up to derive a total score in the ranges of $0-9$ (remission: $<2$, mild: $2-4$, moderate: $5-7$, and severe: $>7$ ). Moderate and severe exacerbations were defined as partial Mayo scores 5-7 and $>7$, respectively. The remission date was defined as the first date after the exacerbation event that we confirmed as clinical improvement according to a partial Mayo $<2$. The re-exacerbation date was defined as the first date after remission that we confirmed a change in clinical status according to a partial Mayo score $\geq 2$.

\section{Assessments of clinical outcomes of corticosteroids}

Clinical outcomes of corticosteroids were evaluated for each exacerbation event. Corticosteroid-refractory was defined if remission, which was assessed according to a partial Mayo score $<2$, could not be achieved by corticosteroid monotherapy. Meanwhile, cases of active disease revival while receiving reduced doses of corticosteroids were regarded as corticosteroid-dependent. We collectively reviewed the cases that showed corticosteroid-refractory or -dependent (COR-REF or DEP) in the analysis.

\section{Definition of effectiveness evaluation and COR-REF or DEP cohorts}

All moderate to severe active events in UC patients were classified as an effectiveness evaluation cohort for assessing the clinical outcomes of treatments during induction of, and maintaining remission after, excluding events that were inducted by 5-ASA alone. COR-REF or DEP cohorts were defined when any of the following conditions were observed: 1) met the abovementioned criteria of COR-REF or DEP after taking corticosteroids for moderate to severe exacerbations or 2) had a previous history of the criteria of COR-REF or DEP inducted for exacerbations using treatments without corticosteroids. 


\section{Statistical analysis}

Pearson's chi-squared test or Fisher's exact test was used, as appropriate. ANOVA test was used to compare the mean between independent groups. The cumulative incidence of surgical resection was analyzed using Kaplan-Meier plots, which was defined as the duration from the date of exacerbation till the date of surgical resection, with the censoring date defined as the day of the last follow-up or the date of re-exacerbation. The cumulative re-exacerbation incidence was analyzed using Kaplan-Meier plots, which was defined as the duration from the date of exacerbation to the date of re-exacerbation, with the censoring date defined as the day of the last follow-up. Cox regression analyses were performed to evaluate the factors for the cumulative risk of surgical resection and re-exacerbation in UC patients with moderate to severe exacerbations. All statistical analyses were conducted using the SPSS statistical software (version 25; SPSS-IBM, Chicago, IL, USA).

\section{Results}

\section{Study population and baseline characteristics}

Between January 2004 and December 2018, 1401 patients were started on treatments for UC at the three institutions and were included in the present retrospective cohort. The final data were locked on December 2019, and the median observation period was 48.3 months (95\% Cl: 44.7-51.9). Supplementary Figure 1 depicts the study population trend per year. The number of follow-up patients per year increased dramatically, and hospitalization rates per year decreased in the present cohort.

Table 1 shows the baseline characteristic of the study population at the time of the initial visit during the study period. The mean age was 39.8 years, and one-fourth of the patients were aged $\leq 22.0$ years. Supplementary Figure 2 presents the correlations between the year of onset and the mean age at initial UC diagnosis. The mean age at initial diagnosis appeared to be significantly higher along with the calendar year of onset $(P<0.001)$. 
Table 1

Baseline characteristics at the initial visit

\begin{tabular}{|c|c|}
\hline Demographics/characteristics & $\begin{array}{l}\text { Any } \\
(n=1401)\end{array}$ \\
\hline Gender, male ( $n[\%])$ & $762(54.4)$ \\
\hline Age at the time of first consultation, years & $39.8(17.3)$ \\
\hline Mean (SD) & $38.0(0-93)$ \\
\hline Median (range) & 26.0 \\
\hline Percentile (25\%) & 38.0 \\
\hline Percentile (50\%) & 52.0 \\
\hline \multicolumn{2}{|l|}{ Percentile (75\%) } \\
\hline Age at the time of initial diagnosis, years & $35.0(16.7)$ \\
\hline Mean (SD) & $31.5(0-93)$ \\
\hline Median (range) & 22.0 \\
\hline Percentile (25\%) & 31.5 \\
\hline Percentile (50\%) & 46.0 \\
\hline \multicolumn{2}{|l|}{ Percentile (75\%) } \\
\hline Height, cm, median (SD) & $162.9(9.7)$ \\
\hline Body weight, kg, median (SD) & $57.0(12.0)$ \\
\hline Body mass index, median (SD) & $19.0(7.6)$ \\
\hline Smoking & $676(48.3)$ \\
\hline None $(n[\%])$ & $186(13.3)$ \\
\hline Previous smoker ( $n[\%])$ & $80(5.7)$ \\
\hline Current smoker ( $n[\%])$ & $459(32.8)$ \\
\hline \multicolumn{2}{|l|}{ Unknown $(n[\%])$} \\
\hline Prior history of appendectomy $(n[\%])$ & $24(1.7)$ \\
\hline Initial diagnosis of UC at the time of first consultation $(n[\%])$ & $419(29.9)$ \\
\hline
\end{tabular}




\begin{tabular}{|c|c|}
\hline Demographics/characteristics & $\begin{array}{l}\text { Any } \\
(n=1401)\end{array}$ \\
\hline Partial Mayo grade at the time of first consultation & $475(33.9)$ \\
\hline Inactive $(n[\%])$ & $451(32.2)$ \\
\hline Mild $(n[\%])$ & $329(23.5)$ \\
\hline Moderate $(n[\%])$ & $146(10.4)$ \\
\hline \multicolumn{2}{|l|}{ Severe $(n[\%])$} \\
\hline Type of UC at the time of first consultation & $367(26.2)$ \\
\hline Proctitis $(n[\%])$ & $368(26.3)$ \\
\hline Left-sided colitis ( $n[\%])$ & $488(34.8)$ \\
\hline Pancolitis ( $n[\%])$ & $95(6.8)$ \\
\hline Right-sided or segmental colitis ( $n$ [\%]) & $83(5.9)$ \\
\hline Unknown $(n[\%])$ & \\
\hline
\end{tabular}

We identified 1639 exacerbation events from the study cohort. Then, 13 exacerbation events were excluded from this analysis due to using tofacitinib for the treatment. Of 1626 exacerbation events to be analyzed, 959 were classified as moderate to severe as follows: 207 in 2004-2008 (21.6\%), 304 in 20092013 (31.7\%), and 448 in 2014-2018 (46.7\%) (Figure 1, upper row). Of the moderate to severe exacerbation events among the entire study population, 878 (91.5\%) were confirmed as remission, and 81 $(8.4 \%)$ were converted into surgical resection without achieving remission.

Next, we extracted the first and second exacerbation events of clinical courses during the observation period for each patient from the overall exacerbation events. Of the identified 994 and 401 first and second exacerbation events during the study period, respectively, 525 and 266 were distinguished as moderate to severe exacerbations, respectively (Figure 1, middle and lower rows). From now on, we will refer to first exacerbation of study period as initial exacerbation, and second exacerbation of study period as relapse exacerbation. Table 2 shows the clinical characteristics of the overall, initial, and relapse exacerbations in patients with moderate to severe active UC. 
Table 2

Clinical characteristics and treatments in patients with moderate to severe UC exacerbations

\begin{tabular}{|llll|}
\hline Characteristics & $\begin{array}{l}\text { Overall } \\
\text { exacerbations } \\
(\mathbf{n}=\mathbf{9 5 9})\end{array}$ & $\begin{array}{l}\text { Initial } \\
\text { exacerbations } \\
\mathbf{( n = 5 2 5 )}\end{array}$ & $\begin{array}{l}\text { Relapse } \\
\text { exacerbations } \\
\mathbf{( n = 2 6 6 )}\end{array}$ \\
\hline Age, year, mean (SD) & $38.6(17.4)$ & $38.1(17.9)$ & $38.3(16.9)$ \\
\hline Partial Mayo, severe (n [\%]) & $246(25.6)$ & $155(29.5)$ & $59(22.2)$ \\
\hline Pancolitis UC (n [\%]) & $403(42.0)$ & $210(40.0)$ & $115(43.2)$ \\
\hline Laboratory data, mean (SD) & $8924.8(3769.8)$ & $9201.2(3891.9)$ & $8736.7(3637.8)$ \\
White blood cell & $3.76(0.71)$ & $3.61(0.79)$ & $3.99(0.532)$ \\
Serum albumin & $2.70(4.36)$ & $3.23(4.83)$ & $2.06(3.42)$ \\
C-reactive protein & & $236(45.0)$ & $85(31.7)$ \\
\hline Hospitalization (n [\%]) & $372(38.8)$ & $292(55.6)$ & $29(10.9)$ \\
\hline $\begin{array}{l}\text { Treatments for exacerbations }(\mathbf{n} \\
\text { [\%]) }\end{array}$ & $330(34.4)$ & $106(20.2)$ & $15(5.6)$ \\
5-ASAs & $124(12.9)$ & $342(65.1)$ & $179(67.2)$ \\
Single use & $628(65.5)$ & $39(7.4)$ & $20(7.5)$ \\
Corticosteroids & $78(8.1)$ & $110(21.0)$ & $61(22.9)$ \\
Immunomodulators & $204(21.3)$ & $55(10.5)$ & $41(15.4)$ \\
Calcineurin inhibitors & $164(17.1)$ & $133(25.3)$ & $78(29.3)$ \\
Biologics & $254(26.5)$ & $42(8.0)$ & $22(8.3)$ \\
Apheresis & $81(8.4)$ & & \\
Surgical resection & & & \\
\hline
\end{tabular}

5-ASA was administered in 330 of 959 moderate to severe exacerbation events (34.4\%), of which 122 $(12.7 \%)$ were treated with 5-ASA alone. Single-use rates of 5-ASA for moderate to severe exacerbations were similar in the three time periods (Figure 2). We excluded those events that were introduced by 5-ASA alone $(n=122)$ and set an effectiveness evaluation cohort in the present study (Figure $1, n=837)$.

Median time periods to remission and re-exacerbation of overall moderate to severe exacerbations in the effectiveness evaluation cohort were 1.7 months $(95 \% \mathrm{Cl}, 1.6-18.9)$ and 36.4 months $(95 \% \mathrm{Cl}, 29.5-$ 43.3), respectively.

Corticosteroids were used for 628 events $(65.5 \%)$ of moderate to severe active UC, of which 126 (13.0\% of overall moderate to severe exacerbations and $20.0 \%$ of inductions by corticosteroids) had a previous history of corticosteroid refractory. The proportions of previous history of COR-REF or DEP were almost in 
concordance with the three time periods (Figure 2, $\mathrm{P}=0.581$ ). During the study period, $56.4 \%$ of events were confirmed as remission by corticosteroids. The remission rates of corticosteroids were significantly higher if there was no previous history of COR-REF or DEP (absence: $60.6 \%$, presence: $39.7 \%, \mathrm{P}<0.001$ ). Of 837 events in the effectiveness evaluation cohort, we classified 360 events as COR-REF or DEP cohort, based on our earlier definition (Figure 1, the rightmost column).

Figure $2 \mathrm{C}$ depicts the transitions of treatments for moderate to severe exacerbations. Biologics showed an increasing tendency during the study period. In contrast, surgical resection and apheresis showed a gradually decreasing trend during same period.

\section{Cumulative risk of surgical resection in UC patients with moderate to severe exacerbations}

Based on the effectiveness evaluation cohort of overall exacerbation events, we analyzed factors for the cumulative risk of surgical resection in patients with moderate to severe active UC. A multivariate Cox regression model revealed age $\geq 60$ years, severe exacerbations, history of COR-REF or DEP, induction by apheresis, and calcineurin inhibitors were independent risk factors for surgical resection (Table 3). On the other hand, steroids tended to reduce the risk of surgery, although the multivariate analysis did not show a significant difference. Biologics had no significant effect on the cumulative risk of surgical resection. 
Table 3

Cox regression analysis of the factors for cumulative risk of surgical resection in patients with moderate to severe UC exacerbations

\begin{tabular}{|c|c|c|c|c|c|c|}
\hline \multirow[t]{2}{*}{ Variables } & \multicolumn{2}{|c|}{ Univariate analysis } & \multirow[t]{2}{*}{$\mathbf{P}$} & \multicolumn{2}{|c|}{ Multivariate analysis } & \multirow[t]{2}{*}{$\mathbf{P}$} \\
\hline & $\begin{array}{l}\text { Hazard } \\
\text { ratio }\end{array}$ & $95 \% \mathrm{Cl}$ & & $\begin{array}{l}\text { Hazard } \\
\text { ratio }\end{array}$ & $95 \% \mathrm{Cl}$ & \\
\hline Age, $\geq 60$ years & 1.895 & $\begin{array}{l}1.133- \\
3.170\end{array}$ & 0.015 & 2.269 & $\begin{array}{l}1.341- \\
3.840\end{array}$ & 0.002 \\
\hline First attack & 0.825 & $\begin{array}{l}0.436- \\
1.560\end{array}$ & 0.554 & 0.997 & $\begin{array}{l}0.511- \\
1.945\end{array}$ & 0.993 \\
\hline Pancolitis UC & 1.432 & $\begin{array}{l}0.924- \\
2.221\end{array}$ & 0.108 & 1.156 & $\begin{array}{l}0.737- \\
1.813\end{array}$ & 0.528 \\
\hline Severe exacerbation & 3.954 & $\begin{array}{l}2.545- \\
6.142\end{array}$ & $<0.001$ & 2.973 & $\begin{array}{l}1.860- \\
4.754\end{array}$ & $<0.001$ \\
\hline $\begin{array}{l}\text { History of COR-REF or } \\
\text { DEP }\end{array}$ & 3.986 & $\begin{array}{l}2.576- \\
6.167\end{array}$ & $<0.001$ & 2.920 & $\begin{array}{l}1.806- \\
4.720\end{array}$ & $<0.001$ \\
\hline Corticosteroids & 0.569 & $\begin{array}{l}0.368- \\
0.879\end{array}$ & 0.011 & 0.666 & $\begin{array}{l}0.419- \\
1.057\end{array}$ & 0.085 \\
\hline Apheresis & 2.021 & $\begin{array}{l}1.302- \\
3.136\end{array}$ & 0.002 & 1.807 & $\begin{array}{l}1.132- \\
2.884\end{array}$ & 0.013 \\
\hline Calcineurin inhibitors & 5.059 & $\begin{array}{l}3.246- \\
7.884\end{array}$ & $<0.001$ & 2.695 & $\begin{array}{l}1.657- \\
4.383\end{array}$ & $<0.001$ \\
\hline Biologics & 1.355 & $\begin{array}{l}0.849- \\
2.164\end{array}$ & 0.203 & 0.913 & $\begin{array}{l}0.556- \\
1.499\end{array}$ & 0.719 \\
\hline
\end{tabular}

We next verified the cumulative incidence of surgical resection in the effectiveness evaluation cohorts of overall, initial, and relapse exacerbation events in subgroups (Figure 3). Classified as COR-REF or DEP were significantly high risk for surgical resection in moderate to severe exacerbation events (Figure 3, the left column). However, biologics did not have a significant effect in reducing the risk for surgical resection (Figure 3, the right column).

\section{Cumulative risk of re-exacerbation in UC patients with moderate to severe exacerbations}

Results of the multivariate Cox regression model in overall moderate to severe exacerbation events in patients with UC are shown in Table 4. Biologics significantly reduced the risk of re-exacerbation. In contrast, induction by corticosteroids significantly increased the risk of re-exacerbation. Figure 4 shows the Kaplan-Meier curve of the cumulative incidence of re-exacerbation caused due to the administration of biologics. Our results confirmed that biologics reduced the risk of re-exacerbation in the whole, initial, and relapse exacerbations population in effective evaluation cohort (Figure 4, the left column). We also 
evaluated that impact of induction of biologics on cumulative incidence rate of re-exacerbation in patients with COR-REF or DEP cohort. The cumulative incidence rate of re-exacerbation in whole exacerbations population was significantly decreased as well as initial exacerbations cohort (Figure 4, the right column).

Table 4

Cox regression analysis of the factors for cumulative risk of re-exacerbation in patients with moderate to severe UC exacerbations

\begin{tabular}{|c|c|c|c|c|c|c|}
\hline \multirow[t]{2}{*}{ Variables } & \multicolumn{2}{|c|}{ Univariate analysis } & \multirow[t]{2}{*}{$\mathbf{P}$} & \multicolumn{2}{|c|}{ Multivariate analysis } & \multirow[t]{2}{*}{$\mathbf{P}$} \\
\hline & $\begin{array}{l}\text { Hazard } \\
\text { ratio }\end{array}$ & $95 \% \mathrm{Cl}$ & & $\begin{array}{l}\text { Hazard } \\
\text { ratio }\end{array}$ & $95 \% \mathrm{Cl}$ & \\
\hline Age, $\geq 60$ years & 0.828 & $\begin{array}{l}0.611- \\
1.115\end{array}$ & 0.214 & 0.813 & $\begin{array}{l}0.603- \\
1.096\end{array}$ & 0.174 \\
\hline First attack & 0.976 & $\begin{array}{l}0.771- \\
1.236\end{array}$ & 0.839 & 0.803 & $\begin{array}{l}0.612- \\
1.054\end{array}$ & 0.113 \\
\hline Pancolitis UC & 1.227 & $\begin{array}{l}1.015- \\
1.484\end{array}$ & 0.035 & 1.217 & $\begin{array}{l}1.065- \\
1.391\end{array}$ & 0.004 \\
\hline Severe exacerbation & 1.238 & $\begin{array}{l}1.000- \\
1.533\end{array}$ & 0.050 & 1.133 & $\begin{array}{l}0.902- \\
1.424\end{array}$ & 0.283 \\
\hline $\begin{array}{l}\text { History of COR-REF or } \\
\text { DEP }\end{array}$ & 0.846 & $\begin{array}{l}0.664- \\
1.077\end{array}$ & 0.173 & 0.930 & $\begin{array}{l}0.716- \\
1.209\end{array}$ & 0.589 \\
\hline 5-ASA & 1.046 & $\begin{array}{l}0.859- \\
1.274\end{array}$ & 0.652 & 1.161 & $\begin{array}{l}0.911- \\
1.480\end{array}$ & 0.226 \\
\hline Corticosteroids & 1.436 & $\begin{array}{l}1.164- \\
1.772\end{array}$ & 0.001 & 1.473 & $\begin{array}{l}1.183- \\
1.833\end{array}$ & 0.001 \\
\hline Apheresis & 0.992 & $\begin{array}{l}0.803- \\
1.226\end{array}$ & 0.944 & 0.977 & $\begin{array}{l}0.785- \\
1.216\end{array}$ & 0.837 \\
\hline Calcineurin inhibitors & 1.115 & $\begin{array}{l}0.886- \\
1.404\end{array}$ & 0.353 & 1.206 & $\begin{array}{l}0.939- \\
1.549\end{array}$ & 0.142 \\
\hline Immunomodulators & 1.051 & $\begin{array}{l}0.754- \\
1.467\end{array}$ & 0.768 & 1.066 & $\begin{array}{l}0.760- \\
1.480\end{array}$ & 0.712 \\
\hline Biologics & 0.527 & $\begin{array}{l}0.389- \\
0.713\end{array}$ & $<0.001$ & 0.501 & $\begin{array}{l}0.367- \\
0.683\end{array}$ & $<0.001$ \\
\hline
\end{tabular}

\section{Discussion}

We demonstrated the effect of biologics in patients with moderate to severe active UC in the Japanese real-world practice by setting two different endpoints, i.e., cumulative incidence rate of surgical resection and re-exacerbation. Our findings indicated the distinctive potential of biologics and the strategic directions of using these drugs in patients. 
This study established a unique endpoint, i.e., the cumulative incidence rate of re-exacerbation, and focused on the clinical impact of biologics on maintaining remission in moderate to severe exacerbation events of UC. In general, the clinical outcomes of biologics were assessed using the remission rate. Most randomized controlled trials of biologics have generally compared with placebo by selecting 44-, 52-, or 54-week remission rate as the primary endpoint [20-24]. Recent studies that confirmed the effectiveness of biologics used similar indicators [29,30]. Even remission rate is a define and convenient endpoint to assess effectiveness both induction and maintenance of remission in UC patients, endpoints with 44-, 52-, or 54-week remission rate appears to be suitable for clinical trials because it does not require long observation periods. However, considering the disease characteristics of UC, the potential of treatments should be evaluated separately based on induction and maintenance of remission. We believe that our study is the first one to demonstrate the cumulative incidence rate of re-exacerbation of biologics in moderate to severe active UC using cohorts from the real-world practice. Our results suggested that administration of biologics significantly reduced the risk of re-exacerbation and prolonged remission duration in moderate to severe UC exacerbation. The cumulative risk of re-exacerbation events, which achieved remission by corticosteroids, was significantly higher than that achieved using biologics in the COR-REF or DEP cohort of our study. Altogether, these results demonstrated an important finding that the conspicuous effect of biologics is maintaining remission in patients with active UC. Based on the results of present study, biologics may be used not only in COR-REF or DEP patients, but also in patients achieving remission by corticosteroids for maintaining remission. We suggest that subpopulation of patients achieving remission by corticosteroids who have high risk of surgical resection in case of reexacerbation have indications for biologics. Although the medical cost of biologics is a huge medical problem [31, 32], biosimilar and generic drugs may help to solve the issue [33]. Further trials focusing on maintaining remission are required to clarify this clinical issue of UC.

Our study also confirmed the potential of corticosteroids in reducing the risk of surgical resection in moderate to severe UC exacerbations, although statistical significance was not observed with the multivariate analysis. Corticosteroids' potential for achieving remission and avoiding surgical resection should be re-recognized in moderate to severe active UC as reported previously $[11-13,18,19]$. Conversely, biologics showed no dramatic impact on reducing surgical resection risk compared with suboptimal treatments in the COR-REF or DEP population. Although a randomized controlled trial verified that infliximab reduced the risk of surgical resection compared with placebo [20], a recent study reported by Murthy et al. demonstrated that anti-TNF therapy did not decrease UC-related intestinal resections in the real-world practice [34]. Altogether, these results and ours indicate that biologics might not have the anticipated effectiveness for introducing remission, especially in salvaging the COR-REF or DEP population from surgical resection. Hence, there is a strong need to develop promising agents with similar or higher potential of achieving remission compared to corticosteroids.

The characteristics of the present retrospective cohort were generally illustrative to represent of the Japanese UC population during the past few decades. First, both the number of UC patients and the median age at onset had been increasing [35-37]. Second, the rates of hospitalization and surgical resection in the entire population had decreased gradually, including other countries as well [26, 38]. 
Surgical resection rates of the present cohort were similar those of a Korean cohort [26], although these rates were lower than those of a Western cohort [39]. Remarkably, the proportion of using immunomodulators (i.e., thiopurines) in the present cohort was lower than that in Western countries [40]. It is well known that the incidence rates of adverse events, primarily leukopenia and hair loss, are higher in East Asian populations, including Japan, than in Caucasian populations [41, 42]. Recently, Moriyama et al. reported that a variant in the nudix hydrolase 15 (NUDT15) gene (R139C, C415C > T) was associated with early severe leukopenia in Asians [43]. Currently, the assessment of NUDT R139C has been approved by the Japanese regulatory authority. Consequently, the opportunity to use thiopurines should increase. It would be necessary to confirm the clinical impact of thiopurines in Japanese UC patients in the near future. Regarding biologics, the administration rate is increasing, as in the rest of the world, and is almost equal or slightly higher than those in other countries due to the well-supported system of medical costs $[26,34]$. Biologics will become more essential agents for treating active UC patients, due to active development of biologics in the coming years $[44,45]$. We anticipate further studies in the future to investigate the effectiveness of biologics focusing on maintaining remission in other cohorts from all over the world.

\section{Conclusion}

Our study has confirmed that biologics significantly improved the duration of maintaining remission compared with suboptimal treatments in patients with moderate to severe active UC in a large retrospective Japanese cohort. However, they could not exert a significant effect in reducing the risk of surgical resection in patients with moderate to severe active UC with corticosteroid refractory. We believe that our study results would help gain a deeper understanding of the characteristics of biologics used for treating UC patients.

\section{Declarations}

Funding: This research did not receive any grants.

\section{Disclosure:}

Sadahisa Ogasawara received honoraria from Bayer, Eisai, Eli Lilly, Otsuka Pharma Co., Ltd., EA Pharma Co., Ltd., consulting or advisory fees from Bayer, Eisai, Merck \& Co., Inc., Chugai Pharma, Eli Lilly, AstraZeneca, and research grants from Bayer, Eisai, Eli Lilly. Naoya Kato received honoraria from Abbvie, Mitsubishi Tanabe Pharma, Nippon Kayaku, Nichi-lko Pharmaceutical Co., Ltd., Takeda, Zeria, Mochida Pharmaceutical Co., Ltd., EA Pharma Co., Ltd., research grants from Abbvie, Mitsubishi Tanabe Pharma, Nippon Kayaku, Takeda, Mochida Pharmaceutical Co., Ltd., EA Pharma Co., Janssen. The other authors involved in this study have nothing to declare regarding funding or conflict of interest with respect to this study. 
Availability of Data and Materials:The datasets used and/or analysed during the current study available from the corresponding author on reasonable request.

IRB did not permit data sharing, because we did not inform patients of data sharing.

\section{Acknowledgments}

We would like to respect and thank all physicians, surgeons, and the other medical staffs in Chiba who have been treating IBD patients enthusiastically since IBDs were rare diseases in Japan.

\section{References}

1. Ungaro R, Mehandru S, Allen PB, et al. Ulcerative colitis. Lancet 2017;389:1756-70.

2. Molodecky NA, Soon IS, Rabi DM, et al. Increasing Incidence and Prevalence of the Inflammatory Bowel Diseases With Time, Based on Systematic Review. Gastroenterology 2012;142:46-54.e30.

3. $\mathrm{Ng} \mathrm{SC}$, Shi HY, Hamidi N, et al. Worldwide incidence and prevalence of inflammatory bowel disease in the 21st century: a systematic review of population-based studies. Lancet 2018;390:2769-78.

4. Thia KT, Loftus EV Jr., Sandborn WJ, et al. An update on the epidemiology of inflammatory bowel disease in Asia. Am J Gastroenterol 2008;103:3167-82.

5. Yang Y, Owyang C, Wu GD. East Meets West: The Increasing Incidence of Inflammatory Bowel Disease in Asia as a Paradigm for Environmental Effects on the Pathogenesis of Immune-Mediated Disease. Gastroenterology 2016;151:e1-e5.

6. Murakami Y, Nishiwaki Y, Oba MS, et al. Estimated prevalence of ulcerative colitis and crohn's disease in japan in 2014: An analysis of a nationwide survey. Journal of Gastroenterology 2019;54:1070-7.

7. Kaplan GG, Ng SC. Understanding and Preventing the Global Increase of Inflammatory Bowel Disease. Gastroenterology 2017;152:313-21.e2.

8. Ng SC, Tang W, Leong RW, et al. Environmental risk factors in inflammatory bowel disease: a population-based case-control study in Asia-Pacific. Gut 2015;64:1063-71.

9. Bressler B, Marshall JK, Bernstein CN, et al. Toronto Ulcerative Colitis Consensus Group. Clinical practice guidelines for the medical management of nonhospitalized ulcerative colitis: the Toronto consensus. Gastroenterology 2015;148:1035-58.e3.

10. Ford AC, Achkar JP, Khan KJ, et al. Efficacy of 5-Aminosalicylates in Ulcerative Colitis: Systematic Review and Meta-Analysis. Am J Gastroenterol 2011;106:601-16.

11. Truelove SC, Witts LJ. Cortisone in ulcerative colitis. BMJ 1955;2:1041-8.

12. Ford AC, Bernstein CN, Khan KJ, et al. Glucocorticosteroid Therapy in Inflammatory Bowel Disease: Systematic Review and Meta-Analysis. Am J Gastroenterol 2011;106:590-9; quiz 600.

13. Garcia-Planella E, Mañosa M, Van Domselaar M, et al. Long-term outcome of ulcerative colitis in patients who achieve clinical remission with a first course of corticosteroids. Dig Liver Dis 
2012;44:206-10.

14. Feuerstein JD, Isaacs KL, Schneider Y, et al. AGA Institute Clinical Guidelines Committee. AGA Clinical Practice Guidelines on the Management of Moderate to Severe Ulcerative Colitis. Gastroenterology 2020;158:1450-61.

15. Matsuoka K, Kobayashi T, Ueno F, et al. Evidence-based clinical practice guidelines for inflammatory bowel disease. J Gastroenterol 2018;53:305-53.

16. Ooi CJ, Fock KM, Makharia GK, et al. Asia Pacific Association of Gastroenterology Working Group on Inflammatory Bowel Disease. The Asia-Pacific consensus on ulcerative colitis. J Gastroenterol Hepatol 2010;25:453-68.

17. Harbord M, Eliakim R, Bettenworth D, et al. Third european evidence-based consensus on diagnosis and management of ulcerative colitis. Part 2: Current management. Journal of Crohn's and Colitis 2017;11:769-84.

18. Järnerot G, Rolny P, Sandberg-Gertzén H. Intensive intravenous treatment of ulcerative colitis. Gastroenterology 1985;89:1005-13.

19. D'Haens G, Lemmens L, Geboes K, et al. Intravenous cyclosporine versus intravenous corticosteroids as single therapy for severe attacks of ulcerative colitis. Gastroenterology 2001;120:1323-9.

20. Rutgeerts P, Sandborn WJ, Feagan BG, et al. Infliximab for Induction and Maintenance Therapy for Ulcerative Colitis. New England Journal of Medicine 2005;353:2462-76.

21. Reinisch W, Sandborn WJ, Hommes DW, et al. Adalimumab for induction of clinical remission in moderately to severely active ulcerative colitis: results of a randomised controlled trial. Gut 2011;60:780-7.

22. Sandborn WJ, van Assche G, Reinisch W, et al. Adalimumab induces and maintains clinical remission in patients with moderate-to-severe ulcerative colitis. Gastroenterology 2012;142:25765.e1-3.

23. Sandborn WJ, Feagan BG, Marano C, et al. PURSUIT-Maintenance Study Group. Subcutaneous golimumab maintains clinical response in patients with moderate-to-severe ulcerative colitis. Gastroenterology 2014;146:96-109.e1.

24. Feagan BG, Rutgeerts $P$, Sands BE, et al. Vedolizumab as Induction and Maintenance Therapy for Ulcerative Colitis. New England Journal of Medicine 2013;369:699-710.

25. Parragi L, Fournier N, Zeitz J, et al. Colectomy Rates in Ulcerative Colitis Are Low and Decreasing: 10year Follow-up Data From the Swiss IBD Cohort Study. Journal of Crohn's and Colitis 2018;12:811-8.

26. Cha JM, Park SH, Rhee KH, et al. Long-term prognosis of ulcerative colitis and its temporal changes between 1986 and 2015 in a population-based cohort in the Songpa-Kangdong district of Seoul, Korea. Gut 2019;gutjnl-2019-319699.

27. Lewis JD, Chuai S, Nessel L, et al. Use of the noninvasive components of the Mayo score to assessclinical response in ulcerative colitis. Inflamm Bowel Dis 2008;14:1660-6 
28. Loftus EV Jr., Silverstein MD, Sandborn WJ, et al. Ulcerative colitis in Olmsted County, Minnesota, 1940-1993: incidence, prevalence, and survival. Gut 2000;46:336-43.

29. Sands BE, Peyrin-Biroulet L, Loftus EV, et al. Vedolizumab versus adalimumab for moderate-to-severe ulcerative colitis. New England Journal of Medicine 2019;381:1215-26.

30. Narula N, Peerani F, Meserve J, et al. Vedolizumab for Ulcerative Colitis: Treatment Outcomes from the VICTORY Consortium. Am J Gastroenterol 2018;113:1345.

31. Wu B, Wang Z, Zhang Q. Cost-Effectiveness of Different Strategies for the Treatment of Moderate-toSevere Ulcerative Colitis. Inflamm Bowel Dis 2018;24:2291-302.

32. Stawowczyk E, Kawalec P. A Systematic Review of the Cost-Effectiveness of Biologics for Ulcerative Colitis. PharmacoEconomics 2018;36:419-34.

33. Meyer A, Rudant J, Drouin J, et al. The effectiveness and safety of infliximab compared with biosimilar CT-P13, in 3112 patients with ulcerative colitis. Aliment Pharmacol Ther 2019;50:269-77.

34. Murthy SK, Begum J, Benchimol El, et al. Introduction of anti-TNF therapy has not yielded expected declines in hospitalisation and intestinal resection rates in inflammatory bowel diseases: a population-based interrupted time series study. Gut 2020;69:274-82.

35. Komoto S, Higashiyama $M$, Watanabe $C$, et al. Clinical differences between elderly-onset ulcerative colitis and non-elderly-onset ulcerative colitis: A nationwide survey data in Japan. J Gastroenterol Hepatol 2018;33:1839-43.

36. Higashiyama M, Sugita A, Koganei K, et al. Management of elderly ulcerative colitis in Japan. J Gastroenterol 2019 Jul;54(7):571-86.

37. Fujimoto T, Kato J, Nasu J, et al. Change of clinical characteristics of ulcerative colitis in japan: Analysis of 844 hospital-based patients from 1981 to 2000. European Journal of Gastroenterology \& Hepatology 2007;19:229-35.

38. Fumery M, Singh S, Dulai PS, et al. Natural History of Adult Ulcerative Colitis in Population-based Cohorts: A Systematic Review. Clin Gastroenterol Hepatol 2018;16:343-56.e3.

39. Frolkis AD, Dykeman J, Negrón ME, et al. Risk of Surgery for Inflammatory Bowel Diseases Has Decreased Over Time: A Systematic Review and Meta-Analysis of Population-Based Studies. Gastroenterology 2013;145:996-1006.

40. Eriksson C, Cao Y, Rundquist S, et al. Changes in medical management and colectomy rates: a population-based cohort study on the epidemiology and natural history of ulcerative colitis in Örebro, Sweden, 1963-2010. Aliment Pharmacol Ther 2017;46:748-57.

41. Hibi T, Naganuma M, Kitahora T, et al. Low-dose azathioprine is effective and safe for maintenance of remission in patients with ulcerative colitis. J Gastroenterol 2003;38:740-6.

42. Takatsu N, Matsui T, Murakami Y, et al. Adverse reactions to azathioprine cannot be predicted by thiopurine S-methyltransferase genotype in Japanese patients with inflammatory bowel disease. $\mathrm{J}$ Gastroenterol Hepatol 2009;24:1258-64. 
43. Moriyama T, Nishii R, Perez-Andreu V, et al. Nudt15 polymorphisms alter thiopurine metabolism and hematopoietic toxicity. Nature Genetics 2016;48:367-73.

44. Sabino J, Verstockt B, Vermeire S, Ferrante M. New biologics and small molecules in inflammatory bowel disease: An update. Therapeutic Advances in Gastroenterology 2019;12:175628481985320.

45. Danese S. New Drugs in the Ulcerative Colitis Pipeline: Prometheus Unbound. Gastroenterology 2020;158:467-70.

\section{Figures}

Figure 1

Study flow

Figure 2

Transitions of treatments in patients with moderate to severe ulcerative colitis exacerbations. A: 5Aminosalicylates, B: Corticosteroids("present" means previous history of COR-REF or DEP), C: Other treatments.

\section{Figure 3}

Cumulative incidences of surgical resection in patients with moderate to severe ulcerative colitis exacerbations. The left column: the impact of classified as COR-REF or DEP cohort on cumulative incidence of surgical resection in patients with the effective evaluation cohort. The right column: impact of induction by biologics on cumulative incidence of surgical resection in patients with the COR-REF or DEP cohort.

\section{Figure 4}

Cumulative incidences of reexacerbations in patients with moderate to severe ulcerative colitis exacerbations. The left column: the impact of induction of biologics on cumulative incidence of reexacerbation in patients with the effectiveness evaluation cohort. The right column: the impact of induction of biologics on cumulative incidence of re-exacerbation in patients with the COR-REF or DEP cohort. 


\section{Supplementary Files}

This is a list of supplementary files associated with this preprint. Click to download.

- SupplFigure1.tiff

- SupplFigure2.tiff

- suppl.docx 